\title{
French science takes stock
}

French government scientists may soon get the opportunity of trying on entrepreneur's clothes. Officials reporting to the French Research Minister, François d'Aubert, plan to change rules that have so far prevented scientists employed by government bodies such as the Centre National de la Recherche Scientifique (CNRS) and the Institut National de la Recherche Medicale (INSERM), from owning shares in companies they may be working with.

Surprising though it may seem to biotechnology communities elsewhere, French scientists in government laboratories are prevented from benefiting from personal incentives like stock or stock options in companies they may be collaborating with. Moreover, if the scientists leave to become involved in entrepreneurial bioscience companies, there is no easy route back into public research positions of similar seniority.

Bioindustrialists believe these factors may account for the relatively slow emergence of an entrepreneurial bioscience sector in France. "There is no opportunity for scientists to get involved in the development of biotech companies without giving up their government research posts," explains Michel Kaczorek, founder and chairman of the new French combinatorial chemistry outfit Synt:em (Nimes, France).

\section{Although France clearly has the potential to be a major force in European biotechnology, many observers believe that the country's science base is currently under utilized.}

However, there is a dichotomy. Although the French officials clearly want to encourage scientists to get involved in the entrepreneurial biotechnology sector by amending the restrictions on share ownership, they also want to establish ground rules to ensure that scientists are not seen to personally enrich themselves at the French taxpayer's expense.
According to Jean-Loup RometLemonne, president of Immuno-Designed Molecules (Paris), there is a general view in France that the prospect of scientists becoming millionaires based on science that the French government paid for would not be well received politically. Nevertheless, it is precisely this same experience that has underpinned much of the growth of new companies in the UK and US.

French private enterprise is also trying to tempt government-backed scientists into the private sector. Although France clearly has the potential to be a major force in European biotechnology-currently it is home to 79 entrepreneurial bioscience firms, the second highest number in Europe after the UK-many observers believe that the country's high-quality science base is currently under utilized. A new forum, dubbed Biotech France (Paris), has now been established by French biotechnology chief executives and venture capitalists-to provide a starting point for scientists looking to establish new businesses as well as a lobbying focus for French biotechnology.

Mike Ward

\section{Controlled release, wide application}

In his plenary address to the 23rd International Symposium on Controlled Release of Bioactive Materials, July 7-10 in Kyoto, Japan, Leslie Benet of the University of California (San Francisco, CA) forecast that in the near future, all drug delivery would be controlled-release formulations. And, according to another speaker, Sung Wan Kim of the University of Utah, (Salt Lake City, UT), novel polymer carriers now hold everyone's interest. The meeting certainly reinforced the notion that scientists in both academia and industry are working to perfect polymer microsphere systems for the delivery of proteins, peptides, and genes (see Lanza et al. pp. 1107-1111).

One of the potential applications for polymer microencapsulation as a drug delivery vehicle is in gene therapy where "nonviral gene therapy, offers a welcome alternative to adenoviral administration," according to Eric Tomlinson, $\mathrm{CEO}$ and president of GeneMedicine (The Woodlands, TX). Microencapsulation in polar lipids, glycopeptide liposomes, or in soluble polymer vesicles could provide controlled release of

Mary Jean Pramik is a freelance writer working in San Rafael, CA. the gene. Scott Walsh and colleagues at the Johns Hopkins University School of Medicine (Baltimore, MD) use gelatin-DNA microspheres to deliver a cystic fibrosis transmembrane conductance regulator

\section{The meeting certainly} reinforced the notion that scientists in both academia and industry are working to perfect polymer microsphere systems for the delivery of proteins, peptides, and genes.

(CFTR) cDNA into the lungs of New Zealand rabbits, a model for cystic fibrosis. They complexed the pSA306 CFTR plasmid with porcine gelatin, using a high-speed vortex mixer to form the microspheres, adding transferrin to target the microspheres to rapidly dividing cells. Successful transfection of the cDNA into the rabbit lung cell, as veri- fied by PCR, was accompanied by thinner lung secretions than the thick viscous mucus found in cystic fibrosis animals. Walsh and his group are now extending the efficacy studies in animals.

Microspheres could also be used as a potential delivery vehicle for "vaccines." Anne Hilbert and colleagues at Philipps-University (Marburg, Germany) showed that, for influenza vaccines, microspheres appear to stabilize the antigen and improve its release kinetics, leading to continuous release of influenza antigens in vitro, at least. Similarly, controlled release may also facilitate cancer "vaccines." Using a cross-linked gelatin/chondroitin sulfate coacervate microsphere formulation, Zhong Zhao and coworkers at Johns Hopkins University administered about a million irradiated B16 melanoma cells and $6 \mu \mathrm{g}$ of radiolabeled cytokine granulocyte-macrophage colony-stimulating factor (GM-CSF) to mice. The controlled release of GM-CSF from the formulation maintained a concentration of GM-CSF above $1 \mathrm{ng} / \mathrm{mg}$ tissue at the vaccine site for over 10 days. This protected the mice against developing tumors from an injection of wild-type B16 tumor cells, twenty-four hours after the initial inoculation. Zhao believes that the gelatin/chondroitin sulfate-based micros- 